\title{
The solution of the problem of free circulation of circular arcs by numerical analytical boundary elements method
}

\author{
Mykola Surianinov $^{1 *}$, Yurii Krutii ${ }^{1}$, Anatolii Kovrov $^{1}$ and Vladimir Osadchiy ${ }^{1}$ \\ ${ }^{1}$ Odessa State Academy of Civil Engineering and Architecture, Didrikson str., 4, Odessa, 65029, \\ Ukraine
}

\begin{abstract}
The work is devoted to determining the natural frequencies and vibration modes of a circular arch using the numerical-analytical boundary elements method. A differential equation of the natural vibrations of the arch is obtained, a complete system of its fundamental solutions is determined, a transcendental frequency equation is constructed, the arch is calculated based on the obtained analytical dependencies, and the results are compared with the results of finite element analysis. For 10 possible combinations of the roots of the equation of the characteristic equation, 360 fundamental functions are calculated. An example of calculating a circular arch for free vibrations by the method of the authors is considered. The search for the roots of the transcendental frequency equation can be carried out by the method of successive approximations, using any programming environment. Here used MATLAB. As a result of the calculation, the first five frequencies of the natural vibrations of the arch were obtained. Their comparison with those calculated in the ANSYS program shows that the spectrum of natural frequencies calculated by the boundary element method is slightly lower (except for the first frequency) than the spectrum calculated by the finite element method, which indicates greater reliability of the results of the boundary element method.
\end{abstract}

\section{Introduction}

Arch structures are used in various fields, such as shipbuilding, aviation, and mechanical engineering. It is possible to name the blades of turbomachines, tires, various aircraft structures, circumferential stiffeners for shell structures. The appearance of new materials has stimulated the use of arch structures in new fields, such as medicine, bioengineering, vibration diagnostics, or the production of nanocomposites. However, arches have been especially widely used in construction, since their use makes it possible to cover long spans.

The first began to erect arches of large size Romans (world-renowned aqueduct Pon-duGar). Well-known old wooden and stone arch bridges in Russia, France, China and many other countries. Modern construction tends to increase the use of steel arches - Abu Dhabi Airport Terminal, Mike O'Callaghan-Pete Tillman Memorial Bridge in America, Charlie's Rail Tunnel in the UK, a new bridge over Ob in Russia and many other unique structures [1].

*Corresponding author: $\underline{\text { sng@ ogasa.org.ua }}$ 
In the technical literature, the issues of statics and stability of arches are quite fully covered, but there are not enough studies about the vibrations of arches. In Russian-language literature, one of the first and most famous is the work of E.S. Sorokin [2], who determined the vibration frequencies of different types of arches by the Ritz method, and then tested the obtained values experimentally. A.B. Morgaevsky [3] obtained the frequency equations of symmetric and inversely symmetric vibrations, for the case when the arch is loaded with radial load. In the following years, there were no significant works on this subject published in Russian or Ukrainian. Foreign literature on the dynamics of rings, arches, arch systems, by contrast, is quite large. The systematization of this literature based on the analysis of more than 400 papers was performed by P. Chidamparam and A.W. Leissa [4]. Most publications in recent decades are related to the use of numerical methods, mainly the finite element method, with the development of a new finite element, or through the use of numerous engineering calculation programs [5-10]. Without diminishing the usefulness of such calculations, it should be noted that they still need verification. Here, too, in our opinion, the application of the numerical-analytical boundary elements method (NA BEM), the main provisions of which are set out in [11-14], is quite effective.

\section{Method}

The purpose of this work is to determine the natural frequencies and vibrations of a circular arch by the numerical-analytical boundary elements method. To achieve this goal, it is necessary to obtain the differential equation of the eigen vibrations of the arch, determine the complete system of its fundamental solutions, perform the calculations of the arch based on the obtained analytical dependencies and compare the results with the results of finite element analysis.

\section{Results and discussion}

The algorithm of application of NA BEM can be divided into two components: "analytical" and "numerical". The first of these is to obtain the analytical expressions of fundamental orthonormal functions, the Green function and the vector of external loads (which in this case will be zero) for all possible roots of the characteristic equation corresponding to the differential equation of the problem [11-14]. After certain transformations of the fundamental equation of the NA BEM [11], we obtain a system of algebraic equations that is solved numerically, and then we can determine the searched values, in this case, the natural frequencies and forms of vibrations.

Consider the free oscillations of a circular arch of constant cross-section drawn along the arc of a circle of radius (Fig. 1). 


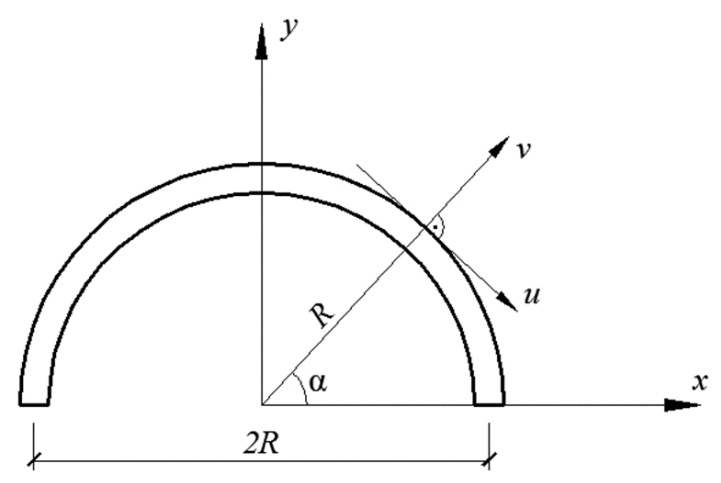

Fig. 1. Circular arch of constant cross-section.

Equilibrium equations have the form [15]

$$
\begin{aligned}
& m R \frac{\partial^{2} v}{\partial t^{2}}+\frac{\partial Q}{\partial \alpha}+N=0 \\
& m R \frac{\partial^{2} u}{\partial t^{2}}+Q-\frac{\partial N}{\partial \alpha}=0
\end{aligned}
$$

where $\alpha$ - the circumferential displacement component, $u-$ radial, $v-$ the angular coordinate of the section.

We differentiate (1) by $\alpha$ and sum with (2):

$$
m R \frac{\partial^{2}}{\partial t}\left(u+\frac{\partial v}{\partial \alpha}\right)+\frac{\partial^{2} Q}{\partial \alpha^{2}}+Q=0
$$

Taking into account that

$$
Q=\frac{1}{R} \cdot \frac{\partial M}{\partial \alpha} ; \quad M=-E I \aleph=-\frac{E I}{R^{2}}\left(\frac{\partial u}{\partial \alpha}-\frac{\partial^{2} v}{\partial \alpha^{2}}\right),
$$

we bring (3) to the form

$$
m R^{2} \frac{\partial^{2}}{\partial t^{2}}\left(u+\frac{\partial v}{\partial \alpha}\right)-\frac{E I}{R^{2}} \frac{\partial}{\partial \alpha}\left(\frac{\partial^{3} u}{\partial \alpha^{3}}-\frac{\partial^{4} v}{\partial \alpha^{4}}+\frac{\partial u}{\partial \alpha}-\frac{\partial^{2} v}{\partial \alpha^{2}}\right)=0
$$

From the condition of non-stretching the axis of the arch follows

$$
v=-\frac{\partial u}{\partial \alpha} \Rightarrow \frac{\partial v}{\partial \alpha}=-\frac{\partial^{2} u}{\partial \alpha^{2}}
$$

then (4) will be written in a form:

$$
m R^{2} \frac{\partial^{2}}{\partial t^{2}}\left(u-\frac{\partial^{2} u}{\partial \alpha^{2}}\right)-\frac{E I}{R^{2}} \frac{\partial}{\partial \alpha}\left(\frac{\partial^{3} u}{\partial \alpha^{3}}+\frac{\partial^{5} u}{\partial \alpha^{5}}+\frac{\partial u}{\partial \alpha}+\frac{\partial^{3} u}{\partial \alpha^{3}}\right)
$$


or

$$
\frac{\partial^{6} u}{\partial \alpha^{6}}+2 \frac{\partial^{4} u}{\partial \alpha^{4}}+\frac{\partial^{2} u}{\partial \alpha^{2}}+\frac{m R^{4}}{E I} \frac{\partial^{2}}{\partial t^{2}}\left(\frac{\partial^{2} u}{\partial \alpha^{2}}-u\right)=0
$$

We will look for a solution (5) in the form

$$
v=v(\alpha) \cos \omega t ; u=u(\alpha) \sin \omega t ; v=-\frac{d u}{d \alpha},
$$

then

$$
\frac{d^{6} u}{d \alpha^{6}}+2 \frac{d^{4} u}{d \alpha^{4}}+\frac{d^{2} u}{d \alpha^{2}}-\frac{m R^{4} \omega^{2}}{E I}\left(\frac{d^{2} u}{d \alpha^{2}}-u\right)=0
$$

or

$$
u^{V I}+2 u^{I V}+u^{I I}-\frac{m R^{4} \omega^{2}}{E I}\left(u^{I I}-u\right)=0 .
$$

Let's present the state vector for the arch in the form

$$
\bar{P}=\left\|\begin{array}{c}
E I v(\alpha) \\
E I \varphi(\alpha) \\
M(\alpha) \\
Q(\alpha) \\
E A u(\alpha) \\
N(\alpha)
\end{array}\right\|
$$

The first four components of the vector (7) determine the bend of the arch, and the last two components - stretching-compression.

We rewrite (6) by grouping the coefficients for the second derivative of the function:

$$
u^{V I}+2 u^{I V}+u^{I I}\left(1-\frac{m R^{4} \omega^{2}}{E I}\right)+\frac{m R^{4} \omega^{2}}{E I} u=0 .
$$

The corresponding characteristic equation:

$$
k^{6}+2 k^{4}+\left(1-\frac{m R^{4} \omega^{2}}{E I}\right) k^{2}+\frac{m R^{4} \omega^{2}}{E I}=0
$$

or

$$
t^{3}+2 t^{2}+z t+(1-z)=0
$$

where 


$$
t=k^{2} ; z=1-\frac{m R^{4} \omega^{2}}{E I}
$$

The solution of equation (8) will depend on the roots of characteristic equation (9). Consider all the possible cases here. From the mathematical point of view, ten cases are possible when solving equation (9); we group them into two groups:

I. One root of the equation (9) $-t_{1}<0$, and for other two there are possible options:

(1) two complex conjugate roots: $t_{2,3}=\alpha \pm i \beta$;

(2) two positive different: $t_{2}>0 ; t_{3}>0$;

(3) two negative different: $t_{2}<0 ; t_{3}<0$;

(4) one positive, the other - negative: $t_{2}>0 ; t_{3}<0$;

(5) two positive equal: $t_{2}=t_{3}>0$;

(6) two negative equal: $t_{2}=t_{3}<0$.

II. One root of the equation (9) $-t_{1}>0$; and for other two there are possible options:

(7) two complex conjugate roots: $t_{2,3}=\alpha \pm i \beta$;

(8) two positive different: $t_{2}>0 ; t_{3}>0$;

(9) two positive equal: $t_{2}=t_{3}>0$;

(10) two negative equal: $t_{2}=t_{3}<0$.

Each root of the characteristic equation gives rise to one private solution of the linear differential equation, and for the construction of the fundamental system of solutions it is necessary to consider in particular the cases of complex roots and cases of multiple roots of the characteristic equation, at that:

- each simple (one-time) real root $k$ in the general solution is matched by the addition of the form $C e^{k \alpha}=C(\operatorname{sh} k \alpha+\operatorname{chk} \alpha)$;

- each pair of the simple complex conjugate roots $k_{1}=\gamma+\delta i, k_{2}=\gamma-\delta i$ in general solution is matched by the addition of the form $e^{\gamma \alpha}\left(C_{1} \cos \delta \alpha+C_{2} \sin \delta \alpha\right)$;

- each $r$-multiple real root $k$ in general solution is matched by the addition of the form $e^{k \alpha}\left(C_{1}+C_{2} \alpha+\ldots+C_{r} \alpha^{r-1}\right)$.

Write the fundamental system of solutions for option (2) of the roots of the characteristic equation:

$$
\begin{aligned}
& t_{1}<0 ; \quad t_{2}>0 ; \quad t_{3}>0 ; \\
& k_{1,2}= \pm i \sqrt{t_{1}} ; \quad k_{3-4}= \pm \sqrt{t_{2}} ; \quad k_{5-6}= \pm \sqrt{t_{3}} .
\end{aligned}
$$

General form of the solution:

$$
u(\alpha)=C_{1} \cos \sqrt{t_{1}} \alpha+C_{2} \sin \sqrt{t_{1}} \alpha+C_{3} \Phi_{1}+C_{4} \Phi_{2}+C_{5} \Phi_{3}+C_{6} \Phi_{4},
$$

where

$$
\Phi_{1}=\operatorname{sh} \sqrt{t_{2}} \alpha ; \Phi_{2}=\operatorname{ch} \sqrt{t_{2}} \alpha ; \Phi_{3}=\operatorname{sh} \sqrt{t_{3}} \alpha ; \Phi_{4}=\operatorname{ch} \sqrt{t_{3}} \alpha
$$


The components of the state vector (7) have the form:

$$
\begin{aligned}
u(\alpha)= & C_{1} \cos \sqrt{t_{1}} \alpha+C_{2} \sin \sqrt{t_{1}} \alpha+C_{3} \operatorname{sh} \sqrt{t_{2}} \alpha+C_{4} \cos \sqrt{t_{2}} \alpha+C_{5} \operatorname{ch} \sqrt{t_{3}} \alpha+C_{6} \operatorname{ch} \sqrt{t_{3}} \alpha \\
& v(\alpha)=u^{\prime}=-C_{1} \sqrt{t_{1}} \sin \sqrt{t_{1}} \alpha+C_{2} \sqrt{t_{1}} \cos \sqrt{t_{1}} \alpha+C_{3} \sqrt{t_{2}} \operatorname{ch} \sqrt{t_{2}} \alpha+ \\
+ & C_{4} \sqrt{t_{2}} \sin \sqrt{t_{2}} \alpha+C_{5} \sqrt{t_{3}} \operatorname{ch} \sqrt{t_{3}} \alpha+C_{6} \sqrt{t_{3}} \operatorname{sh} \sqrt{t_{3}} \alpha \\
& v^{\prime}(\alpha)=u^{\prime \prime}=-C_{1} t_{1} \cos \sqrt{t_{1}} \alpha-C_{2} t_{1} \sin \sqrt{t_{1}} \alpha+C_{3} t_{2} \operatorname{sh} \sqrt{t_{2}} \alpha+C_{4} t_{2} \operatorname{ch} \sqrt{t_{2}} \alpha+ \\
+ & C_{5} t_{3} \operatorname{sh} \sqrt{t_{3}} \alpha+C_{6} t_{3} \operatorname{ch} \sqrt{t_{3}} \alpha ; \\
& v^{\prime \prime}(\alpha)=u^{\prime \prime \prime}=C_{1} t_{1} \sqrt{t_{1}} \sin \sqrt{t_{1}} \alpha-C_{2} t_{1} \sqrt{t_{1}} \cos \sqrt{t_{1}} \alpha+C_{3} t_{2} \sqrt{t_{2}} \operatorname{ch} \sqrt{t_{2}} \alpha+ \\
& +C_{4} t_{2} \sqrt{t_{2}} \operatorname{sh} \sqrt{t_{2}} \alpha+C_{5} t_{3} \sqrt{t_{3}} \operatorname{ch} \sqrt{t_{3}} \alpha+C_{6} t_{3} \sqrt{t_{3}} \operatorname{sh} \sqrt{t_{3}} \alpha ; \\
v^{\prime \prime \prime} & (\alpha)=u^{I V}=C_{1} t_{1}^{2} \cos \sqrt{t_{1}} \alpha+C_{2} t_{1}^{2} \sin \sqrt{t_{1}} \alpha+C_{3} t_{2}^{2} \operatorname{sh} \sqrt{t_{2}} \alpha+C_{4} t_{2}^{2} \operatorname{ch} \sqrt{t_{2}} \alpha+ \\
+ & C_{5} t_{3}^{2} \operatorname{sh} \sqrt{t_{3}} \alpha+C_{6} t_{3}^{2} \operatorname{ch} \sqrt{t_{3}} \alpha ; \\
v^{I V} & (\alpha)=u^{V}=-C_{1} t_{1}^{2} \sqrt{t_{1}} \sin \sqrt{t_{1}} \alpha+C_{2} t_{1}^{2} \sqrt{t_{1}} \cos \sqrt{t_{1}} \alpha+C_{3} t_{2}^{2} \sqrt{t_{2}} \sin \sqrt{t_{2}} \alpha+ \\
+ & C_{4} t_{2}^{2} \sqrt{t_{2}} \operatorname{sh} \sqrt{t_{2}} \alpha+C_{5} t_{3}^{2} \sqrt{t_{3}} \operatorname{ch} \sqrt{t_{3}} \alpha+C_{6} t_{3}^{2} \sqrt{t_{3}} \operatorname{sh} \sqrt{t_{3}} \alpha .
\end{aligned}
$$

As an expression for $N$ in (7) we use the equilibrium equation:

$$
N=-\frac{d Q}{d \alpha}-q_{y}(\alpha) R
$$

As a rule, $q_{y}(\alpha)=0$ at $\alpha=0$ (the exception is when in cross section $\alpha=0$ the concentrated force is applied, which is quite rare in practice), so we will start from the ratio:

$$
N=-\frac{d Q}{d \alpha}=-E I v^{I V}
$$

Constant $C_{1} \div C_{6}$ we will define from the matrix relation:

$$
\bar{\Phi}_{0} \bar{C}_{i}=\bar{P}_{0}, i=1,2, \ldots, 6
$$

Kinematic and static factors of state vector (7) are defined in the form:

$$
\left\{\begin{array}{l}
v=u^{\prime} ; \\
N=-E I v^{I V} \\
\varphi=v^{\prime} ; \\
M=E I v^{\prime \prime} ; \\
Q=E I v^{\prime \prime \prime}
\end{array}\right.
$$


Substituting $\alpha=0$ into (10) - (15), we get:

\begin{tabular}{|c|c|c|c|c|c|}
\hline 0 & $\sqrt{t_{1}}$ & $\sqrt{t_{2}}$ & 0 & $\sqrt{t_{3}}$ & 0 \\
\hline$-t_{1}$ & 0 & 0 & $t_{2}$ & 0 & $t_{2}$ \\
\hline 0 & $-t_{1} \sqrt{t_{1}}$ & $t_{2} \sqrt{t_{2}}$ & 0 & $t_{3} \sqrt{t_{3}}$ & 0 \\
\hline$t_{1}^{2}$ & 0 & 0 & $t_{2}^{2}$ & 0 & $t_{3}^{2}$ \\
\hline 1 & 0 & 0 & 1 & 0 & 1 \\
\hline 0 & $-\sqrt{t_{1}} t_{1}^{2}$ & $-t_{2}^{2} \sqrt{t_{2}}$ & 0 & $-t_{3}^{2} \sqrt{t_{3}}$ & 0 \\
\hline
\end{tabular}

\begin{tabular}{|c|c|}
\hline$C_{1}$ & $E I v_{0}$ \\
\hline$C_{2}$ & $E I \varphi_{0}$ \\
\hline$C_{3}$ & $M_{0}$ \\
\hline$C_{4}$ & $Q_{0}$ \\
\hline$C_{5}$ & $E I u_{0}$ \\
\hline$C_{6}$ & $N_{0}$ \\
\hline
\end{tabular}

It follows from (16) that the system of six algebraic equations for determining constants splits $C_{1} \div C_{6}$ into two independent systems of three equations in each:

$$
\begin{aligned}
& \left\{\begin{array}{l}
\sqrt{t_{1}} C_{2}+\sqrt{t_{2}} C_{3}+\sqrt{t_{3}} C_{5}=v_{0} ; \\
-t_{1} \sqrt{t_{1}} C_{2}+t_{2} \sqrt{t_{2}} C_{3}+t_{3} \sqrt{t_{3}} C_{5}=M_{0} ; \\
-t_{1}^{2} \sqrt{t_{1}} C_{2}-t_{2}^{2} \sqrt{t_{2}} C_{3}-t_{3}^{2} \sqrt{t_{3}} C_{5}=N_{0} .
\end{array}\right. \\
& \left\{\begin{array}{l}
-t_{1} C_{1}+t_{2} C_{4}+t_{3} C_{6}=\varphi_{0} ; \\
t_{1}^{2} C_{1}+t_{2}^{2} C_{4}+t_{3}^{2} C_{6}=Q_{0} ; \\
C_{1}+C_{4}+C_{6}=u_{0} .
\end{array}\right.
\end{aligned}
$$

As a result of solution (17) and (18) we find:

$$
\left\{\begin{array}{l}
C_{1}=\frac{t_{2} t_{3}}{\left(t_{1}+t_{2}\right)\left(t_{1}+t_{3}\right)} u_{0}-\frac{\left(t_{3}-t_{2}\right)}{\left(t_{1}+t_{2}\right)\left(t_{1}+t_{3}\right)} \varphi_{0}+\frac{1}{\left(t_{1}+t_{2}\right)\left(t_{1}+t_{3}\right)} Q_{0} ; \\
C_{2}=\frac{t_{2} t_{3}}{\sqrt{t_{1}\left(t_{1}+t_{2}\right)\left(t_{1}+t_{3}\right)}} v_{0}-\frac{\left(t_{3}+t_{2}\right)}{\sqrt{t_{1}}\left(t_{1}+t_{2}\right)\left(t_{1}+t_{3}\right)} M_{0}-\frac{1}{\sqrt{t_{1}\left(t_{1}+t_{2}\right)\left(t_{1}+t_{3}\right)}} N_{0} ; \\
C_{3}=\frac{-t_{1} t_{3}}{\sqrt{t_{2}}\left(t_{1}+t_{2}\right)\left(t_{2}-t_{3}\right)} v_{0}+\frac{\left(t_{1}-t_{3}\right)}{\sqrt{t_{2}\left(t_{1}+t_{2}\right)\left(t_{2}-t_{3}\right)} M_{0}-\frac{1}{\sqrt{t_{2}\left(t_{1}+t_{2}\right)\left(t_{2}-t_{3}\right)}} N_{0} ;} \\
C_{4}=\frac{t_{1} t_{3}}{\left(t_{3}-t_{2}\right)\left(t_{1}+t_{2}\right)} u_{0}+\frac{\left(t_{3}-t_{1}\right)}{\left(t_{3}-t_{2}\right)\left(t_{1}+t_{2}\right)} \varphi_{0}-\frac{1}{\left(t_{3}-t_{2}\right)\left(t_{1}+t_{2}\right)} Q_{0} ; \\
C_{6}=\frac{t_{1} t_{2}}{\sqrt{t_{3}}\left(t_{2}-t_{3}\right)\left(t_{1}+t_{3}\right)} v_{0}-\frac{\left(t_{1}-t_{2}\right)}{\sqrt{t_{3}\left(t_{2}-t_{3}\right)\left(t_{1}+t_{3}\right)} M_{0}+\frac{1}{\sqrt{t_{3}\left(t_{1}+t_{3}\right)\left(t_{2}-t_{3}\right)}} N_{0} ;} u_{0}+\frac{\left(t_{1}-t_{2}\right)}{\left(t_{1}+t_{3}\right)\left(t_{3}-t_{2}\right)} \varphi_{0}+\frac{1}{\left(t_{1}+t_{3}\right)\left(t_{3}-t_{2}\right)\left(t_{3}-t_{2}\right)} Q_{0} .
\end{array}\right.
$$


After calculating the constants $C_{1} \div C_{6}$ we can calculate all the fundamental functions of the problem for the considered variant of the roots of the characteristic equation (9). For example, for displacement $v(\alpha)$ we have:

$$
\begin{gathered}
v(\alpha)=u^{\prime}=A_{11} v_{0}+A_{12} \varphi_{0}+A_{13} M_{0}+A_{14} Q_{0}+A_{15} u_{0}+A_{16} N_{0} . \\
A_{11}=\frac{t_{2} t_{3} \cos \sqrt{t_{1}} \alpha}{\left(t_{1}+t_{2}\right)\left(t_{1}+t_{3}\right)}-\frac{t_{1} t_{3} \operatorname{ch} \sqrt{t_{2}} \alpha}{\left(t_{1}+t_{2}\right)\left(t_{2}-t_{3}\right)}+\frac{t_{1} t_{2} c h \sqrt{t_{3}} \alpha}{\left(t_{2}-t_{3}\right)\left(t_{1}+t_{3}\right)} \\
A_{12}=\frac{\left(t_{3}-t_{2}\right) \sqrt{t_{1}} \sin \sqrt{t_{1}} \alpha}{\left(t_{1}+t_{2}\right)\left(t_{1}+t_{3}\right)}+\frac{\left(t_{3}-t_{1}\right) \sqrt{t_{2}} \operatorname{sh} \sqrt{t_{2}} \alpha}{\left(t_{3}-t_{2}\right)\left(t_{1}+t_{2}\right)}+\frac{\left(t_{1}-t_{2}\right) \sqrt{t_{3}} c h \sqrt{t_{3}} \alpha}{\left(t_{1}+t_{3}\right)\left(t_{3}-t_{2}\right)} \\
A_{13}=-\frac{\left(t_{3}+t_{2}\right) \cos \sqrt{t_{1}} \alpha}{\left(t_{1}+t_{2}\right)\left(t_{1}+t_{3}\right)}+\frac{\left(t_{1}-t_{3}\right) \operatorname{ch} \sqrt{t_{2}} \alpha}{\left(t_{1}+t_{2}\right)\left(t_{2}-t_{3}\right)}-\frac{\left(t_{1}-t_{2}\right) \operatorname{ch} \sqrt{t_{3}} \alpha}{\left(t_{2}-t_{3}\right)\left(t_{1}+t_{3}\right)} \\
A_{14}=-\frac{\sqrt{t_{1}} \sin \sqrt{t_{1}} \alpha}{\left(t_{1}+t_{2}\right)\left(t_{1}+t_{3}\right)}-\frac{\sqrt{t_{2}} s h \sqrt{t_{2}} \alpha}{\left(t_{3}-t_{2}\right)\left(t_{1}+t_{2}\right)}+\frac{\sqrt{t_{3}} c h \sqrt{t_{3}} \alpha}{\left(t_{1}+t_{3}\right)\left(t_{3}-t_{2}\right)} \\
A_{15}=-\frac{t_{2} t_{3} \sqrt{t_{1}} \sin \sqrt{t_{1}} \alpha}{\left(t_{1}+t_{2}\right)\left(t_{1}+t_{3}\right)}+\frac{t_{1} t_{3} \sqrt{t_{2}} s h \sqrt{t_{2}} \alpha}{\left(t_{3}-t_{2}\right)\left(t_{1}+t_{2}\right)}-\frac{t_{1} t_{2} \sqrt{t_{3}} s h \sqrt{t_{3}} \alpha}{\left(t_{1}+t_{3}\right)\left(t_{3}-t_{2}\right)} \\
A_{16}=-\frac{\cos \sqrt{t_{1}} \alpha}{\left(t_{1}+t_{2}\right)\left(t_{1}+t_{3}\right)}-\frac{c h \sqrt{t_{2}} \alpha}{\left(t_{1}+t_{2}\right)\left(t_{2}-t_{3}\right)}+\frac{c h \sqrt{t_{3}} \alpha}{\left(t_{2}-t_{3}\right)\left(t_{1}+t_{3}\right)}
\end{gathered}
$$

Similarly, the other 30 fundamental functions for this variant of the roots of the characteristic equation (9) are determined. For all the above 10 variants of the roots of equation (9), 360 fundamental functions are calculated.

Now, following the usual algorithm of boundary element solution [11], we can determine

\begin{tabular}{|c|c|c|}
\hline $\begin{array}{c}E I v(0)=0 \\
M(\alpha)\end{array}$ & \multirow{6}{*}{-} & $E I v(\alpha)=0$ \\
\hline $\begin{array}{c}E I \varphi(0)=0 \\
Q(\alpha)\end{array}$ & & $E I \varphi(\alpha)=0$ \\
\hline$M(0)$ & & $M(\alpha)$ \\
\hline$Q(0)$ & & $Q(\alpha)$ \\
\hline $\begin{array}{c}E I u(0)=0 \\
N(\alpha)\end{array}$ & & $\operatorname{EIu}(\alpha)=0$ \\
\hline$N(0)$ & & $N(\alpha)$ \\
\hline
\end{tabular}
all the parameters of the state vector (7).

Consider an example of calculating a circular arch for free vibrations by the method of boundary elements. With respect to the calculation scheme (Fig. 2), the solution of the NA BEM equation for the boundary value problem for the eigen vibrations of the arch by the boundary element method takes the form:

\begin{tabular}{|l|l|l|l|l|l|}
\hline & & $A_{13}$ & $A_{14}$ & & $A_{16}$ \\
\hline & & $A_{23}$ & $A_{24}$ & & $A_{26}$ \\
\hline-1 & & $A_{33}$ & $A_{34}$ & & $A_{36}$ \\
\hline & -1 & $A_{43}$ & $A_{44}$ & & $A_{46}$ \\
\hline & & $A_{53}$ & $A_{54}$ & & $A_{56}$ \\
\hline & & $A_{63}$ & $A_{64}$ & -1 & $A_{66}$ \\
\hline
\end{tabular}



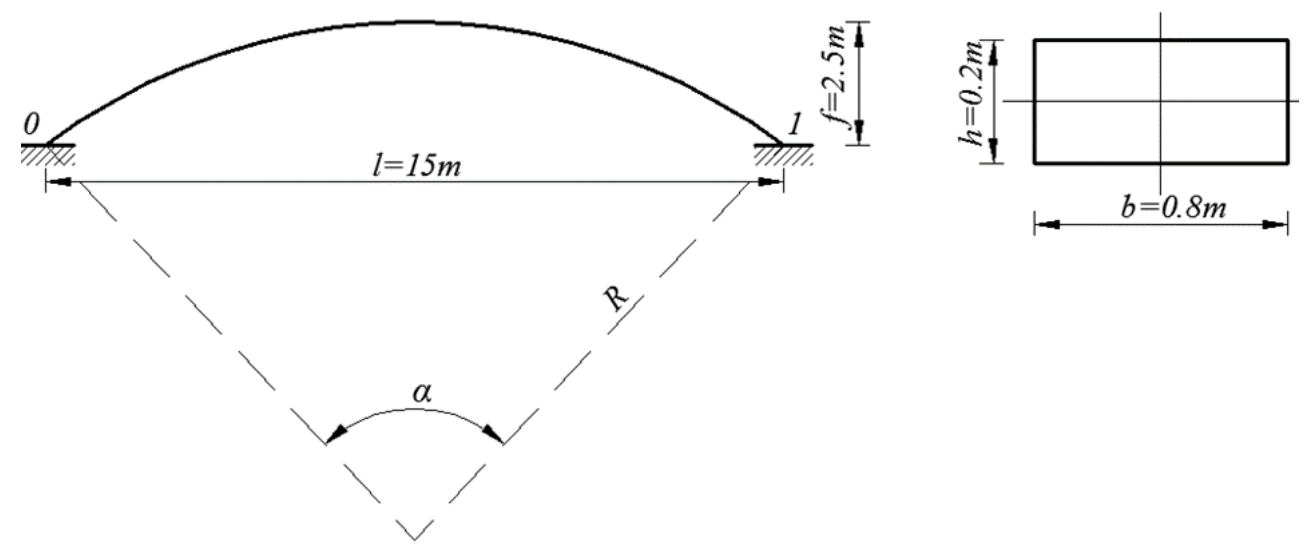

Fig. 2. Example of arch calculation.

Since at the eigen vibrations the boundary parameters vector $X_{*}(0, \alpha) \neq 0$, equation (19) have non-zero solutions at condition

$$
\left|A_{*}(\omega, \alpha)\right|=0
$$

Equation (20) will be the transcendental frequency equation of the BEM for the arch (Fig. 2 ). The roots of this equation are the frequencies of the natural vibrations of the arch. Root searches can be done using sequential approximation using any programming environment. As a result of the calculation, the frequencies of the natural vibrations of the arch were obtained. The number of frequencies that can be calculated can be any.

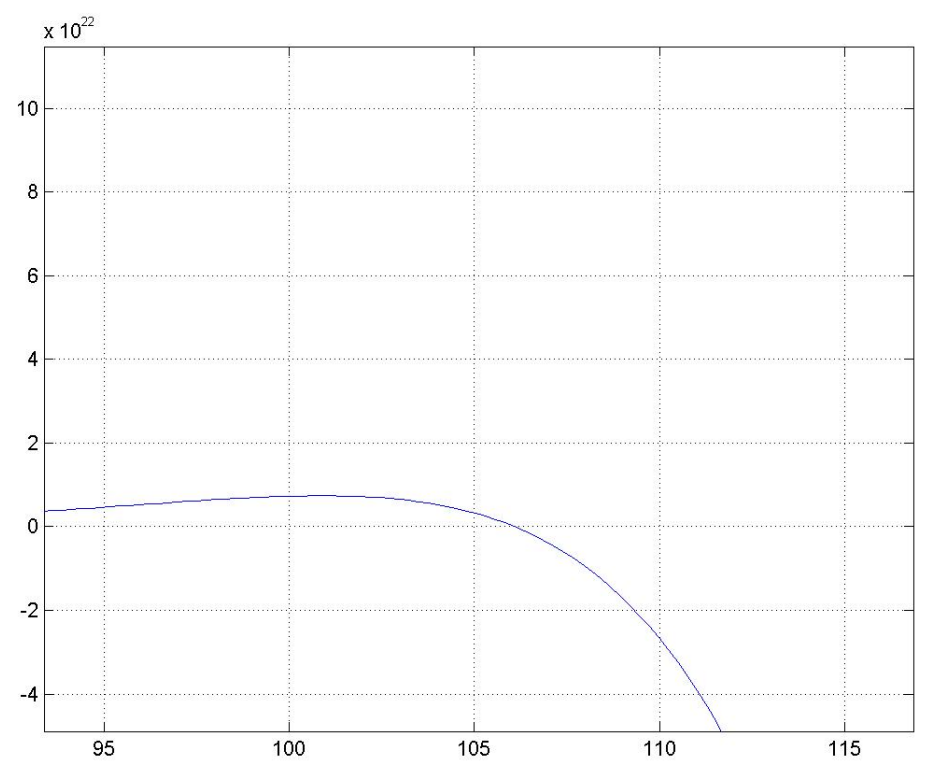

Fig. 3. Determination of the second frequency of vibration.

Frequency spectrum is determined by plotting the frequency determinant of frequency; the points of intersection of this graph with the horizontal axis are natural frequencies. Each 
frequency can be calculated with almost any accuracy. As an example, Fig. 3 shows the process of calculating the second frequency (the program is implemented in MATLAB). Now for each frequency it is possible to determine the parameters of the state vector of the arch by the expressions above. A comparison of the first five natural frequencies determined by the NA BEM algorithm with those calculated in ANSYS is given in Table 1.

Table 1. NA BEM and FEM results comparison.

\begin{tabular}{|c|c|c|c|}
\hline $\begin{array}{c}\text { Frequency } \\
\text { number }\end{array}$ & BEM, s ${ }^{-1}$ & FEM, $^{-1}$ & Discrepacy, $\%$ \\
\hline 1 & 65,625 & 65,069 & 0,85 \\
\hline 2 & 106,080 & 106,618 & 0,51 \\
\hline 3 & 206,819 & 208,119 & 0,62 \\
\hline 4 & 271,575 & 274,559 & 1,09 \\
\hline 5 & 341,290 & 345,714 & 1,28 \\
\hline
\end{tabular}

\section{Conclusion}

The analysis of the Table 1 shows that the spectrum of natural frequencies calculated by the boundary element method is slightly lower (except for the first frequency) than the spectrum calculated by the finite element method, which indicates a greater likelihood of the NA BEM results.

When calculating a particular arch system, the parameter $\mathrm{z}$ in (9) can be calculated with the precision with which the frequency of natural vibrations is calculated. Therefore, it is necessary to set the frequency change interval, for example, $(0,2000) \mathrm{s}-1$, after which, in the course of implementing the calculation program in any programming language, an automatic transition to the calculation of fundamental functions corresponding to the roots of characteristic equation (9) is made.

The program that realizes the calculation of the arch system by the boundary element method in accordance with the described methodology, is quite voluminous, but it is connected with a large number of arithmetic operators and logical branches. In fact, the cost of computing resources is minimal, because we have to solve a system of only twelve algebraic equations, which is significantly less than using the finite element method.

\section{References}

1. Murzintsev P P, Kosarev N S, Nikonov A V, 2015 Primenenie sputnikovyih GNSStehnologiy dlya obespecheniya nadvizhki arki Bugrinskogo mosta cherez reku Ob (Novosibirsk: Interekspo-Geo-Sibir vol 1 issue 1) pp 72-76

2. Sorokin E S, 1939 Kolebaniya arok vol 1 pp 107-110

3. Morgaevskiy A B, 1955 O kolebaniyah krugovoy arki v napravlenii, perpendikulyarnom $\mathrm{k}$ ee ploskosti vol 22

4. Chidamparam P and Leissa A W, 1993 Vibrations of planar curved beams, rings, and arches vol 46 no 9 pp 467-483

5. Palaninathan R and Chandrasekharan P S, 1985 Curved beam element stiffness matrix formulation Comput. Struct. 21 pp 663-669 
6. Ryu H S and Sin H C, 1996 Curved beam elements based on strained fields Commun. Numer. Methods Eng. 12 pp 767-773

7. Litewka P and Rakowski J, 1997 An efficient curved beam finite element Int. J Numer Methods Eng. 40 pp 2629-2652

8. Litewka P and Rakowski J, 1998 The exact thick arch finite element Comput. Struct. 68 pp 369-379

9. Iman Dayyani, Michael I Friswell, Erick I Saavedra Flores, 2014 A general super element for a curved beam. Int. Journal of Solids and Structures 51 pp 2931-2939

10. Wu J S, Lin F T, Shaw H J, 2013 Free in-plane vibration analysis of a curved beam (arch) with arbitrary various concentrated elements Applied Mathematical Modelling 37 pp 7588-7610

11. Daschenko A F, Kolomiets L V, Orobey V F, Surianinov N G, 2010 Chislennoanaliticheskiy metod granichnyih elementov (Odessa: VMV) vol 1 p 416, vol 2 p 512

12. Orobey V F, Surianinov N G, 2011 Praktikum po resheniyu kraevyih zadach mehaniki (Odessa: Astroprint) p 408

13. Daschenko A F, Orobey V F and Surianinov N G, 2011 MATLAB v mehanike deformiruemogo tverdogo tela. Algoritmyi i programmyi (Harkov: Burun kniga) p 480

14. Orobey V F, Surianinov N G, 2011 Osnovnyie polozheniya chislenno-analiticheskogo varianta MGE (St. Petersburg: St. Petersburg Polytechnic Universities Press) vol 4(22) pp 33-39

15. Surianinov M G, Daschenko O F, BIlous V O, 2003 TeoretichnI osnovi dinamIki mashin (Odessa: Bahva) p 308

16. Lalin V.V., Dmitriev A.N., Dyakov S.F. Geometricheski nelineynoe deformirovanie i ustoychivost uprugih arok. Inzhenerno-stroitelnyiy zhurnal. 2019. Vol. 5(89). Pp. 3951. DOI: 10.18720/MCE.89.4 (rus)

17. Le T., Lalin V.V., Bratashov A.A. Staticheskiy uchet vyisshih mod kolebaniy v zadachah dinamiki konstruktsiy. Inzhenerno-stroitelnyiy zhurnal. 2019. Vol. 4(88). Pp. 3-13. DOI: 10.18720/MCE.88.1 (rus)

18. Wu J.S., Lin F.T., Shaw H.J. Free in-plane vibration analysis of a curved beam ( $\operatorname{arch})$ with arbitrary various concentrated elements. Applied Mathematical Modelling. 2013. Vol. 37. Pp. 7588-7610. 